\title{
AVALIAÇÃO DA RESPOSTA IMUNE E HISTOLOGIA DA BOLSA CLOACAL EM FRANGOS VACINADOS COM VACINA VETORIAL HVT-IBD E DESAFIADOS COM CEPA MOULTHROP G603 DO VIRUS DA DOENÇA DE GUMBORO
}

\author{
(Evaluation of immune response and histology of cloacal bursa in broilers vaccinated \\ with a HVT-IBD vector vaccine and challenged with Gumboro Disease virus strain \\ Moulthrop G603)
}

Bruna Luiza Belote ${ }^{1}$, Patrick Westphal, Larissa Pickler, Antonio Leonardo Kraieski, Elizabeth Santin ${ }^{1}$

${ }^{1}$ Programa de Pós-Graduação em Ciências Veterinárias. Setor de Ciências Agrárias. Universidade Federal do Paraná.

*Correspondência: santin@ufpr.br

RESUMO: O objetivo deste estudo foi avaliar a resposta imunológica de frangos de corte frente a uma vacina vetorial HVT-IBV com posterior desafio com a cepa Moulthrop G603 aos 21 ou 28 dias de vida. Foram realizadas análises macroscópicas e histológicas da bolsa cloacal e quantificação de células imunológicas no baço (linfócitos B, T CD4+ e CD8+), bolsa cloacal (linfócitos T CD3+) e no sangue (linfócitos B, T CD4 de mucosa e T CD8 ativados). Aos 35 dias de idade, aves desafiadas aos 21 e 28 dias de idade, submetidas ou não a vacina vetorial, apresentaram maior contagem $(P<0,05)$ de linfócitos $T$ CD3+ na bolsa cloacal que aves não desafiadas e não vacinadas. Aves vacinadas e desafiadas apresentaram maior preservação do tecido da bolsa cloacal $(P<0,05)$ e significativa redução de linfócitos $\mathrm{CD} 4+$ no baço quando comparadas aos demais grupos. Aves desafiadas aos 28 dias de idade apresentaram maior população de células $B, T$ CD4+ e T CD8+ no baço e menor concentração de células imunológicas no sangue quando comparada a aves desafiadas aos 21 dias $(P<0,05)$. Os resultados demonstram que a vacina vetorial HVT-IBV modifica a dinâmica imune e preserva 0 tecido da bolsa cloacal.

Palavras-chave: citometria de fluxo; imunoistoquímica; doença da bolsa cloacal; linfócitos B; linfócitos T

ABSTRACT: This study was carried out to evaluate a vector vaccine HVT-IBV in birds challenged with the strain Moulthrop G603 at 21 and 28 days of age. Histological analyses of the cloacal bursa and the presence of immune cells in the spleen (B, T CD4+ and T CD8+ lymphocytes), the cloacal bursa (T CD3+ lymphocytes) and the blood (B lymphocyte, mucosa TCD4 and activated T CD8) was evaluated. At 35 days of age, challenged birds at 21 and 28 days of age vaccinated or not presented a significantly higher number of T CD3+ in cloacal bursa than non-challenge and non-vaccinated birds. Challenged and vaccinated birds presented more preserved cloacal bursa tissue $(\mathrm{P}<0.05)$ and significantly reduction on T CD4+ lymphocytes in spleen when compared to the other groups. Birds challenged at 28 days of age presents higher population of B, T CD4+ and T CD8+ in spleen and less concentration of immune cells in blood when compared to birds challenged at 21 days of age at 7 days post-challenge $(P<0.05)$. Based on our 
results the vector vaccine HVT-IBV change the immune cell dynamic and preserve the cloacal bursa tissue.

Key Words: flow cytometry; immunohistochemistry; infectious bursal disease; B lymphocytes; T lymphocytes

\section{INTRODUÇÃO}

O vírus da doença de Gumboro (IBDV) pertence a família Birnaviridae responsável por causar a doença infecciosa da Bolsa Cloacal (IBD), mais comumente conhecida como doença de Gumboro. Esta é uma doença imunossupressora e acomete principalmente aves jovens (Berg 2000). Os sinais clínicos associados à doença aguda incluem anorexia, depressão, penas arrepiadas, diarreia, prostração e morte (Berg 2000), além de interferir nos mecanismos normais de coagulação sanguínea. Dessa maneira, as lesões mais frequentes desta doença incluem atrofia da bolsa cloacal, desidratação, hemorragias nos músculos da coxa, do peito e da bolsa cloacal (Mahgoub 2012), afetando economicamente a produção comercial de frangos (Muller et al., 2012).

A patogênese e a resposta imune para o IBDV podem variar dependendo da idade da ave afetada e da maturidade do seu sistema imune (Rautenschlein et al., 2007). O vírus pode causar mortalidade de $20 \%$ ou mais em frangos a partir de três semanas de idade, e severa e prolongada imunossupressão em frangos infectados precocemente, resultando em infecções secundárias nos plantéis não protegidos (Schat e Skinner, 2008; Balamurugan e Kataria, 2006; Lukert e Saif, 2003; Corley et al., 2002).

Está bem estabelecido que em aves com mais de duas semanas de idade, a infecção com IBDV induz um acúmulo de linfócitos $T$ na Bolsa Cloacal (BC), o alvo principal do vírus, coincidindo com a replicação viral (Rautenschlein et al., 2007), com função de realizar o clearance viral e, consequentemente a recuperação do tecido bursal (Carballeda et al., 2011; Willians e Davison, 2005; Sharma et al., 2000).

O vírus da IBD é altamente infeccioso e bastante resistente à inativação. $O$ controle desta enfermidade é realizado principalmente por meio de programas de biosseguridade e vacinação em matrizes e frangos de corte. Porém mesmo a vacinação com vírus atenuado pode levar a imunossupressão (Sahar et al., 2004), principalmente relacionado à depleção de BC. Além disso, a vacinação de frangos de corte pode sofrer efeito de anticorpos maternais (AMs), impedindo ou reduzindo seu potencial de gerar uma resposta imune efetiva.

Com intuito de auxiliar na prevenção da IBD de forma mais efetiva, novas tecnologias e vacinas de segunda geração têm sido desenvolvidas e introduzidas no mercado (Meeusen et al., 2007). Atualmente utilizam-se vacinas vetoriais ou recombinantes, disponíveis comercialmente utilizando um Herpes Vírus de Peru (HVT) como vetor, um vírus muito estável e seguro utilizado mundialmente para prevenção da doença de Marek (Zhou et al., 2010). A proteína VP2 é extraída de um IBDV doador e é inserida no genoma do HVT, este ao se replicar expressa a proteína do IBDV e induz proteção ao animal vacinado. O HVT utilizado na vacina é não patogênico e tem como hospedeiro natural espécies aviárias (Zhou et al., 
2010). Quando se administra a vacina vetorial, o vetor segue o curso normal da patogênese e atua nos mesmos locais de replicação da ave. Ao fazê-lo, o próprio vetor e a proteína inserida são apresentados ao sistema imunológico e estes estimulam a proteção necessária contra as enfermidades desejadas (Le Gros et al., 2009).

O objetivo do presente estudo foi avaliar a dinâmica das células imunológicas, no baço, sangue e bolsa cloacal em frangos desafiados aos $21 \mathrm{e}$ 28 dias de vida com cepa forte de IBDV, vacinadas ou não com vacina vetorial HVT-IBD contra doença de Gumboro.

\section{MATERIAL E METODOS}

O experimento foi conduzido com a aprovação do Comitê de Ética Animal do Setor de Ciências Agrárias da Universidade Federal do Paraná. Protocolo no 020/2011.

As aves foram pesadas individualmente no primeiro dia para distribuição proporcional em relação ao peso corporal entre os tratamentos, permitindo parcelas iguais entre os mesmos. Cada tratamento foi alojado em salas isoladores idênticas com pressão negativa e com temperatura controlada de acordo com a fase de desenvolvimento das aves. Todas as salas passaram por processo de limpeza e desinfecção prévia e a cama de maravalha utilizada foi previamente esterilizada em autoclave 121\%/15 minutos. A água e o alimento foram fornecidos ad libitum e consistiu em dieta balanceada à base de milho e soja formulada conforme recomendado pelo NRC (1994).

Foram alojados 100 frangos de corte, machos da linhagem $\mathrm{Cobb} \AA$, do $1^{\circ}$ ao $35^{\circ}$ dia de idade, divididas em um experimento fatorial 2 (com e sem vacina) $X 2$ (desafio aos 21 ou 28 dias), composto por quatro tratamentos com 5 repetições contendo inicialmente 5 aves em cada de acordo com Tabela 1.

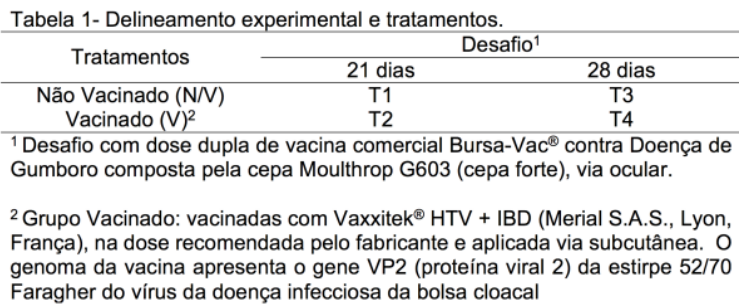

${ }^{2}$ Grupo Vacinado: vacinadas com Vaxxitek ${ }^{\circledast}$ HTV + IBD (Merial S.A.S., Lyon, França), na dose recomendada pelo fabricante e aplicada via subcutânea. $\mathrm{O}$ genoma da vacina apresenta o gene VP2 (proteína viral 2) da estirpe 52/70

Faragher do vírus da doença infecciosa da bolsa cloacal

Foram utilizadas como grupo controle negativo $(\mathrm{CN})$ para análise de bolsa coaclal 10 aves de mesma origem e linhagem que não receberam desafio nem vacinação, criadas sob as mesmas condições do experimento. Os resultados da avaliação dos tecidos dessas aves estavam de acordo com os padrões normais descritos na literatura para histologia de bolsa cloacal (Bacha Jr. e Bacha, 2003; Aughey e Frye, 2001).

Ao primeiro dia foram coletados soros de 20 aves para avaliação sorológica para Doença de Gumboro, visando avaliar a imunidade materna transferida aos pintinhos.

Aos 21 e 28 dias de idade as aves, de acordo com os tratamentos apresentados na Tabela 1, foram desafiadas com dose dupla de vacina comercial Bursa-Vac $\AA$ Intervet $\AA$, contra Doença de Gumboro composta pela cepa forte Moulthrop G603, via ocular. Cada ave recebeu por dose um título médio de $2 \times 10^{1,3} \mathrm{DIOE}_{50}$ (dose Infectante $50 \%$ em ovos embrionados), conforme descrição do fabricante.

Ao longo de todo o período experimental as aves foram avaliadas diariamente para presença de sinais clínicos e mortalidade.

Aos 35 dias, todas as aves foram eutanasiadas por deslocamento cervical para análise macroscópica dos órgãos (lesões em sacos aéreos, traqueia, fígado, musculatura e rins). Também foi realizada a aferição de bolsa cloacal com auxílio de um paquímetro e 
coletado amostras de baço e bolsa cloacal para análises histológicas.

As observações macroscópicas foram avaliadas levando em conta lesões típicas da doença de Gumboro previamente descritas por Eterradossi e Saif (2008), onde o grau de severidade das lesões (GSDG) recebeu maior classificação quanto mais patognomônicas fossem em relação a essa doença. As lesões avaliadas à necropsia receberam escores entre 0 e 3 , conforme a intensidade apresentada. Os valores de escores foram multiplicados pelo GSDG estabelecendo um valor máximo para cada tipo de lesão conforme descrito na Tabela 2.

Tabela 2- Classificação do grau de severidade das lesões macroscópicas avaliadas

\begin{tabular}{ccc}
\hline Alteração Patológica & GSDG $^{1}$ & Escore Máximo \\
\hline Hemorragia Muscular & 2 & 6 \\
Alterações Renais & 2 & 6 \\
Alterações Hepáticas & 1 & 3 \\
Aerossaculite & 1 & 3 \\
Alterações na Traqueia & 1 & 3 \\
\hline Escore final & & 21
\end{tabular}

${ }^{1}$ GSDG - Grau de severidade relacionado a doença de Gumboro. 0 escore para cada lesão foi obtido pela multiplicação do GSDG pelo escore de lesões observadas à necropsia $(0=$ ausência, $1=$ presente em pequena quantidade, 2=presente em quantidade intermediária $3=$ presente em grande quantidade/difusa). $O$ escore final para os sinais macroscopicos foram obtidor

relos escores individuais, podendo atingir o máximo de 21 pontos.

Durante a necropsia foram coletadas bolsas cloacais de 10 aves por grupo que foram acondicionadas em formol tamponado $10 \%$ para análise histológica com coloração de Hematoxilina-eosina (HE). Foram avaliados quatro campos por fragmento de bolsa cloacal em aumento de 10X em microscópio óptico (Olympus America INC., NY, USA), totalizando 40 avaliações por tratamento. Avaliou-se perda de arquitetura tecidual, presença de vacuolização e substituição de tecido normal por tecido conjuntivo.

A classificação dos escores de lesão na bolsa cloacal, foram tomadas levando em conta o método anteriormente publicado por Kolf-Clauw et al. (2009) adaptado para o tecido da bolsa cloacal. As lesões previamente descritas na literatura receberam escores conforme grau de intensidade de 0-3, multiplicado pelo grau de severidade relacionado à doença de Gumboro (GSDG), conforme Tabela 3.

Tabela 3- Classificação dos escores de lesão versus grau de severidade das lesões avaliadas em Bolsa Cloacal na Histopatologia.

\begin{tabular}{ccc}
\hline \multicolumn{1}{c}{ Alteração Patológica } & GSDG $^{1}$ & $\begin{array}{c}\text { Escore } \\
\text { Máximo }\end{array}$ \\
\hline $\begin{array}{c}\text { Vacuolização celular, núcleos } \\
\text { picnóticos e perda de estrutura dos } \\
\text { folículos }\end{array}$ & 3 & 9 \\
$\begin{array}{c}\text { Substituição de tecido integro por } \\
\text { tecido conjuntivo }\end{array}$ & 3 & 9 \\
\hline Escore final & 18 \\
\hline 1 GSDG - Grau de Severidade em relação a Doença de Gumboro. O
\end{tabular}

${ }^{1}$ GSDG - Grau de Severidade em relação a Doença de Gumboro. O escore para cada lesão foi obtido pela multiplicação do GSDG pelo escore de lesões observadas à necropsia $(0=a u s e ̂ n c i a, 1=p r e s e n t e$ em pequena quantidade, $2=$ presente em quantidade intermediária $e$ $3=$ presente em grande quantidade/difusa) 0 escore final para sinais típicos de IBD no quado da bolsa cloacal, foram obtidos $p$ da soma dos escores individuais, podendo atingir um máximo de 18 pontos.

Para as análises de linfócitos T CD3+, as amostras foram incluídas em parafina, seccionadas com $5 \mu \mathrm{m}$ de espessura e fixadas em lâminas carregadas positivamente. As seções foram desparafinadas em xilol a $60^{\circ} \mathrm{C}$ por 20 minutos e re-hidratadas em água e álcool. A recuperação antigênica foi realizada com Tampão Citrato $\mathrm{pH} 6,0$ em banho-maria a $100^{\circ} \mathrm{C}$ por 10 minutos e o bloqueio da peroxidase endógena com peróxido de hidrogênio $3 \%$ e proteína bloqueadora por 8 minutos. 0 anticorpo primário utilizado foi Anti-CD3 (CD3 Dako® 1:750), incubado em refrigerador overnight. Para detecção da reação foi utilizado anticorpos secundários anti-camundongo e anticoelho combinados num mesmo sistema de amplificação, kit ADVANCE $\AA$, por 30 minutos. Para revelação da reação utilizou-se cromógeno, kit $\mathrm{DAB} \AA$, por 30 segundos. As lâminas foram contra-coradas com Hematoxilina de Meyer, lavadas em água com posterior desidratação e montagem das mesmas.

A mensuração das células CD3+ na bolsa cloacal foi realizada por meio de contagem do número de células coradas em campo microscópico de 100X. Foram analisadas contagens de 20 campos/grupo. 
Para as análises de linfócitos $B, T$ CD4+ e CD8+, amostras de baço foram incluídas em gel Tissue-Tek O. C. T. (Miles, Elkhart IN, US), congeladas em nitrogênio líquido, seccionadas com 5 $\mu \mathrm{m}$ de espessura em criostato e fixadas em lâminas carregadas positivamente em acetona $100 \%$. Em seguida foi realizada a re-hidratação com PBS $0,1 \mathrm{M}$ $\mathrm{pH} 7,6$, bloqueio da peroxidase endógena com peróxido de hidrogênio $3 \%$ por 5 minutos e proteína bloqueadora por 8 minutos. Os anticorpos primários utilizados foram Anti-CD4 (CT-4 Southern Biotech®) $1: 200)$ e Anti-CD8 (CT-8 Southern Biotech® 1:200), Anti-Linfócito B (Bu1 Southern Biotech ${ }^{\circledR}$ 1:100) incubados por 90 minutos a $37^{\circ} \mathrm{C}$. Para detecção da reação foi utilizado anticorpos secundários anti-camundongo e anticoelho combinados num mesmo sistema de amplificação, kit ADVANCE $®$, por 30 minutos. Para revelação da reação utilizou-se cromógeno, kit $\mathrm{DAB} B$, por 30 segundos. As lâminas foram contra-coradas com Hematoxilina de Meyer, lavadas em água com posterior desidratação e montagem das mesmas.

Para a mensuração das quantidades de linfócitos $B$, linfócitos $T$ CD4+ e CD8+, foram analisados 15 campos microscópicos por tratamento em aumento de 40X, onde as subáreas ocupadas pelas células marcadas em marrom recebiam valores por meio de software analisador de imagens (Motic Image Plus 2.0 - Motic China Group Co. 2006), ao final estas subáreas eram somadas obtendo-se a área ${ }^{2}$ total ocupada por linfócitos num campo microscópico com área ${ }^{2}$ total de $24100 \mu \mathrm{m}^{2}$.

Para análise de citometria de fluxo, foi coletado sangue de 6 aves por tratamento, sendo os grupos T1 e T2 avaliadas aos $18^{\circ}$ e $28^{\circ}$ dias e aves dos grupos T3 e T4 avaliadas aos $25^{\circ}$ e $35^{\circ}$ dias, ou seja, 3 dias antes do desafio
$(A D)$ e 7 dias pós do desafio (PD) com a cepa forte Moulthrop, conforme metodologia previamente descrita por (Beirão et al. 2012). Brevemente, as células mononucleares foram separadas do sangue total através de gradiente de densidade usando Histopaque-1077 (Sigma-Aldrich). O sangue foi diluído 1:1 com solução de PBS para volume total de $2 \mathrm{~mL}$. Esta diluição foi mergulhada em $3 \mathrm{~mL}$ de Histopaque-1077 em tubo de $15 \mathrm{~mL}$. As amostras foram centrifugadas em $400 \mathrm{~g}$, por 30 minutos em temperatura ambiente. $\mathrm{O}$ buffy coat resultantes de células brancas acima dos eritrócitos foi então coletado e transferido para outro tubo de $15 \mathrm{~mL}$. As células foram lavadas duas vezes com 4 $\mathrm{mL}$ de PBS e centrifugado a $400 \mathrm{~g}$ por 7 minutos. $O$ sedimento final foi ressuspenso em $1 \mathrm{~mL}$ de solução de paraformaldeído em PBS 1\% para a fixação das células. Trinta minutos após a ressuspensão, as células foram centrifugadas a $400 \mathrm{~g}$ por 7 minutos, 0 sobrenadante foi descartado, as células foram lavadas duas vezes com PBS e centrifugado a mesma velocidade $\mathrm{e}$ tempo e sedimento final foi ressuspenso em PBS com BSA 1\%. As células foram contadas utilizando uma câmara de contagem de Neubauer. Coloração única foi realizada para todos os anticorpos, usando $2 \mu \mathrm{L}$ do anticorpo primário diluído em $20 \mathrm{~mL}$ de PBS $(\mathrm{pH}$ 7,4 ). Esta diluição foi misturada com $10^{6}$ células mononucleares e mantido à temperatura ambiente no escuro por 20 minutos. Após este período de incubação, as células foram lavadas com $2 \mathrm{~mL}$ de PBS, centrifugado a $400 \mathrm{~g}$ por 7 minutos. O sobrenadante foi descartado. As células receberam o anticorpo secundário $(5 \mu \mathrm{L}$ diluição de 1:200) ou Estreptavidina FITC (diluídos $1 \mathrm{~mL}: 10 \mu \mathrm{L}$ de PBS), de acordo com a exigência. As células foram mantidas por 20 minutos em temperatura ambiente no escuro, e em seguida lavado com $2 \mathrm{~mL}$ de PBS e 
centrifugado. $O$ sedimento final foi ressuspenso em $250 \mu \mathrm{L}$ de PBS com BSA $1 \%$. Todas as amostras passaram por citometria de 2 horas de coloração. A citometria de fluxo foi realizada em um citômetro de fluxo FACSCalibur (Becton Dickinson). Flurescência verde (fluorescência de FITC) foi detectada no canal FL1 (nm 530/30), e fluorescência laranja foi detectada no canal FL2 (nm 585/42). As células foram analisadas em até 10.000 eventos no gate de linfócitos (com base na frente e dispersão lateral), inclusive contaminando trombócitos. Os dados foram analisados com o software FlowJo.

As amostras foram analisadas utilizando os anticorpos CD4+TCRVb1+ (CD4 de mucosa), CD8+CD28- (CD8 ativado) e Bu1 (Linfócitos B). Os resultados foram transformados como porcentagem de células positivas em relação ao total de células leucocitárias de cada animal.

Todos os dados coletados foram analisados pelo programa estatístico Statistix for Windows Copyright@ 2008. Os resultados foram submetidos ao teste de normalidade de Shapiro-Wilk. Como os resultados apresentaram distribuição normal, estes dados foram avaliados por meio de ANOVA e em seguida comparados pelo teste de Tukey $(P<0,05)$.

\section{RESULTADOS E DISCUSSÃO}

$\begin{gathered}\text { Durante todo o período do } \\ \text { observado }\end{gathered}$
experimento não foi doença de
mortalidade relacionada à doentaram
Gumboro. Prévios estudos reportaram
que aves desafiadas e não vacinadas
apresentam mortalidade, rue
dependendo da estirpe viral pode
chegar a 100\% (Scanavini Neto et al.
2004). Porém, outros estudos (Haddad
et al., 1997, Sharma et al., 2000)
também não observaram mortalidade
em aves desafiadas com cepas
clássicas e virulentas do vírus da

doença de Gumboro em condições experimentais.

As aves apresentaram no exame sorológico um título médio de 1617,21 para doença de Gumboro. Os títulos avaliados apresentaram boa uniformidade de acordo com a fórmula de Deventer (De Wit 2001) e mostraram uma boa uniformidade de títulos com cerca de cinco dias de diferença entre a vacinação da ave com menor título para a ave com maior título. A fórmula também mostrou que a data ideal para vacinação com resposta de $75 \%$ das aves, com vacina do tipo intermediária plus seria aos 13 dias de idade, coincidindo com a queda dos anticorpos maternais a níveis que não interferissem com 0 vírus vacinal. A imunidade passiva, transferida pela matriz à progênie é de suma importância para prevenção da doença de Gumboro (Michell et al., 2009), porém ela pode interferir com a imunidade vacinal. Dessa forma a avaliação sorológica da progênie é importante para o estabelecimento da idade correta de vacinação.

Para os resultados de análise de bolsa cloacal não houve interação entre os fatores vacina e período de desafio. Durante avaliação macroscópica das aves aos 35 dias de idade, não foram observadas diferenças entre os tratamentos para lesões macroscópicas de bolsa cloacal, porém aves vacinadas e desafiadas apresentaram menor escore de lesões histológicas e maior área de bolsa cloacal quando comparada a aves não vacinadas e desafiadas (Tabela 4). A semelhança deste resultado, Perozo et al. (2009) observaram que aves SPF desafiadas com a cepa $\mathrm{E}$ do vírus da Doença de Gumboro e vacinadas com vacina vetorial no primeiro dia de vida apresentaram lesões menos severas em bolsa cloacal quando comparadas com aves não vacinadas, indicando proteção conferida pela vacina. No presente 
estudo o escore de lesão histológica de aves vacinadas e desafiadas foi semelhante à de aves não vacinadas e não desafiadas (Tabela 4), indicando que a vacina vetorial não promove lesões significativas histológicas passíveis de serem observadas em aves de 35 dias de vida e ainda protege das lesões provocadas pelo desafio com a cepa forte vacinal Moulthrop.

A replicação viral na bolsa cloacal estimula a resposta imunológica, sendo possível observar maior quantidade de linfócitos $T$ CD3+/campo na bolsa cloacal de aves desafiadas, vacinadas ou não, quando comparada ao grupo controle não vacinado e não desafiado (Tabela 4). Em estudos prévios, a população de linfócitos CD3+, CD4+ e $\mathrm{CD} 8 \alpha+\beta+$ em bolsa cloacal de aves desafiadas com IBDV foi avaliada por meio de citometria de fluxo e observouse aumento dessas células aos 5 dias após infecção quando comparado ao grupo não desafiado, porém aos 28 dias após o desafio já não foi possível observar diferenças na população celular entre aves desafiadas ou não (Carballeda et al. 2014).

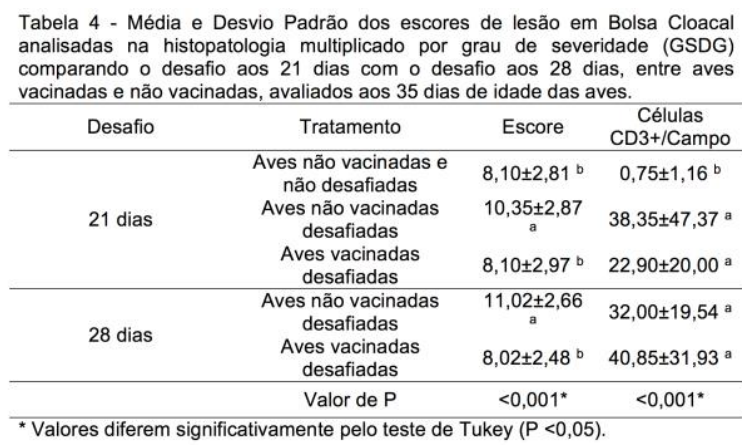

Quando se avalia os resultados de área de linfócitos $\mathrm{B}, \mathrm{T}$ CD4+ e T CD8+ em baço de aves desafiadas com cepa forte Moulthrop G603 aos 21 ou 28 dias de idade é possível verificar que houve interação entre os fatores vacinação e período de desafio para todos estes parâmetros (Tabela 5). Aves vacinadas e desafiadas aos 21 dias apresentara menor área de Linfócitos $\mathrm{B}$ e de linfócitos T CD8+ que os demais tratamentos e ainda apresentou menor área de linfócitos T CD4+ que aves não vacinadas e desafias aos 28 dias. Jeurissen et al. (1998) indica que pode ocorrer migração de células imunológicas para outros órgãos como bolsa cloacal e baço como resultado da replicação viral, cinco dias após infecção com o vírus da doença de Gumboro. Estes resultados sugerem que é possível que aves vacinadas e desafiadas aos 21 dias de idade tiveram diminuição desta replicação viral no baço, o que resultou em menor área de células imunológicas no baço, 14 dias após o desafio comparada ao grupo não vacinado e desafiado no mesmo período. Quando as aves foram desafiadas aos 28 dias, essa mesma relação não pode ser observada, pelo curto período de tempo entre o desafio e momento de avaliação ( 7 dias após 0 desafio), sendo necessário estudos mais longos para melhor avaliar esse processo.

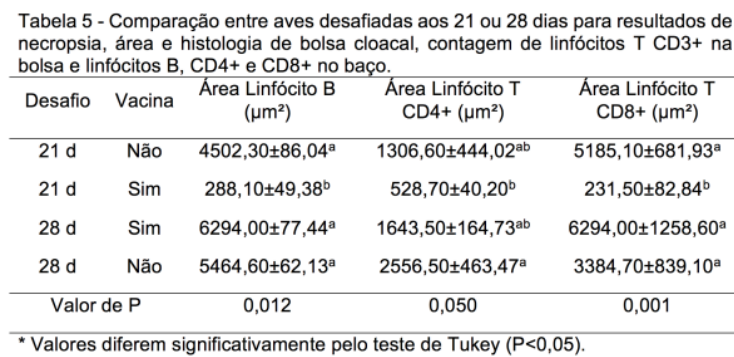

A Tabela 6 apresenta os resultados da avaliação das células imunológicas no sangue por meio de citometria de fluxo em aves desafiadas aos 21 ou 28 dias de idades, vacinadas ou não com vacina vetorial. As análises foram realizadas aos 3 dias antes do desafio e 7 dias após o desafio. É possível observar que aves desafiadas aos 21 dias de idade apresentaram quantidade significativamente maior de linfócitos B, T CD4 de mucosa e T CD8 ativado quando comparadas com aves desafiadas aos 28 dias de idade. Aves desafiadas aos 28 dias de idade 
apresentaram menor concentração de células imunológicas no sangue e aumento de células B, CD4+ e CD8+ no baço, indicando migração das células imunológicas da circulação sanguínea para um dos órgãos alvo do IBDV. É observado na literatura que infecções virais podem ocasionar redução de células imunológicas no sangue periférico e aumento dessas nos tecidos alvo (Williams e Davison 2005, Beirao et al., 2012).

Não foi observada diferença significativa entre aves vacinadas ou não com vacina vetorial para células $T$ CD8 (ativado) e Linfócitos B circulantes, mas aves vacinadas apresentaram menor quantidade de células T CD4 de mucosa quando comparado a aves não vacinadas. A literatura aponta resultados controversos com relação a população de células CD4 no sangue de aves vacinadas. Jakka et al. 2014, observaram que aves vacinadas com cepa intermediária e intermediária plus apresentaram aumento de células $T$ CD4 no sangue. Porém outros autores reportaram redução ou não alteração na população destas células no sangue de aves (Rodenberg et al., 1994). Jakka et al. (2014) relatou aumento de células CD8+ no sangue de aves vacinados contra IBDV, porém no presente estudo esta diferença não foi observada entre os grupos vacinados ou não.

Aos 3 dias antes do desafio aves apresentaram quantidade significativamente menor de linfócitos $T$ CD8 ativados quando comparados a aves 7 dias após desafio com cepa forte Moulthrop G603, mas esses valores de células CD8+ foram maiores aos 7 dias em aves desafiadas aos 28 dias que aves desafiadas aos 21 dias.

\section{CONCLUSÃO}

O desafio não foi capaz de reproduzir nas aves sinais clínicos típicos da doença de Gumboro entre os

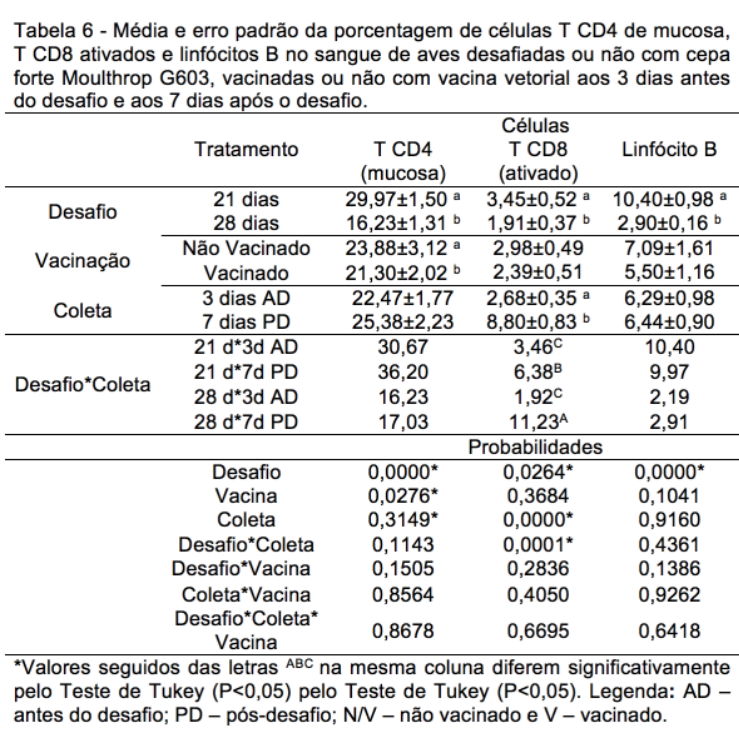

diferentes grupos avaliados, porém foi capaz de induzir lesões típicas da doença representada pela depleção linfoide do tecido da bolsa cloacal. Aves desafiadas com cepa forte Moultrop G603 aos 21 e 28 dias de idade, submetidas ou não a vacina vetorial, apresentaram maior população de linfócitos T CD3+ na bolsa cloacal que aves não desafiadas e não vacinadas. Aves submetidas vacina vetorial e desafiadas com cepa forte Moultrop G603 apresentaram lesões histológicas menos severas em bolsa cloacal e redução de linfócitos CD4+, CD8+ e linfócitos $B$ no baço, quando desafiadas aos 21 dias comparado a aves desafiadas não vacinadas aos 21 dias sugerindo proteção contra a replicação viral nestes órgãos 14 dias após 0 desafio. Aves desafiadas aos 28 dias de idade apresentaram menor população de células B, CD4+ e CD8+ circulantes no sangue comparado com aves desafiadas aos 21 dias, indicando que a migração dessas células para órgãos como o baço diminui aos 7 dias após desafio.

\section{REFERENCIAS}

AUGHEY, E., FRYE, F.L. Lymphatic System. in: AUGHEY, E., FRYE, F.L. Comparative Veterinary Histology - 
With Clinical Correlates, Manson Publishing, 2001, p.258.

BACHA JR. W.J., BACHA, L.M. Sistema Linfático. in: BACHA, W.J. AND BACHA, L.M. Atlas Colorido de Histologia Veterinária, 2 ed., Roca, pp., 2003, 111138

BALAMURUGAN, V., KATARIA, J.M. Economically important non-oncogenic Immunosuppressive viral diseases of chicken - currentstatus. Veterinary Research Communication. 30, 541566. 2006.

BEIRAO, B.C.; FAVARO, C. JR.; NAKAO, L.S. et al. Flow cytometric immune profiling of specific-pathogenfree chickens before and after infectious challenges. Veterinary Immunology Immunopathology. 145:32-41. 2012.

BERG, T.P.V.D. Acute infectious bursal disease in poultry: A review. Avian Pathology. 29:175-194. 2000.

CARBALLEDA, J.M.; ZOTH, S.C.; GÓMEZ, E. et al. Immune response elicited by the oral administration of an intermediate strain of IBDV in chickens. Brazilian Journal Microbiology. 45:1521-1525. 2014.

CORLEY, M., GIAMBRONE, J.J., DORMITORIO, T.V. Evaluation of the immune response and detection of infectious bursal disease viruses by reverse transcriptase - polymerase chain reaction and enzyme-linked immunosorbent assay after in ovo vaccination of commercial broilers. Avian Disease. 46: 803-809. 2002.

DE, WIT, J.J. Gumboro Disease: Estimation ofoptimal time of vaccination by the Deventer formula. Proceedings of the 3rd meeting of working group 3of COST action 839: passive protection andvaccination (current and future possibilities) in the presence of maternally derived antibody. Pulawy, pp: 21-28. 2001.
ETERRADOSSI, N.; SAIF, Y.M. Infectious Bursal Disease. In: SAIF, Y.M., FADLY, A.M., GLISSON, J.R., MCDOUGALD, L.R., NOLAN, L.K., SWAYNE DE. Diseases of poultry. 12th ed. Ames: lowa State University Press, 2008, p.185-208.

HADDAD, $\quad$ E.E, WHITFILL, C.E, AVAKIAN, A.P. et al. Efficacy of a novel infectious bursal disease virus immune complex vaccine in broiler chickens. Avian Disease. Oct-Dec; 41(4):882-9. 1997

JAKKA, P.; REDDY Y.K.; KIRUBAHARAN J.J. et al. Evaluation of immune responses by live infectious bursal disease vaccines to avoid vaccination failures. European Journal Microbiology Immunollogy. 4:123-127. 2014.

JEURISSEN, S.H.; JANSE, E.M.; LEHRBACH, P.R. et al. The working mechanism of an immune complex vaccine that protects chickens against infectious bursal disease. Immunology. 95:494-500. 1998.

KOLF-CLAUW, M.; CASTELLOTE, J.; JOLY, B.; BOURGES-ABELLA, N. et al. Development of a pig jejunal explant culture for studying the gastrointestinal toxicity of the mycotoxin deoxynivalenol: histopathological analysis. Toxicology in vitro. 23:1580-1584. 2009.

LE GROS, F.X., DANCER, A., GIACOMINI, C. et al. Field efficacy trial of a novel HVT-IBD vector vaccine for 1 day-old broilers. Vaccine. 27:592-596. 2009.

LUKERT, P.D., SAIF, Y.M. Infectious bursal disease virus. in: SAIF, Y.M, BARNES, H.J., GLISSON, J.R., FADLY, A.M., MCDOUGALD, L.R., SWAYNE, D.E. Diseases of Poultry. Ames: lowa State University Press, 2003, pp. 161179. 
MAHGOUB, $\mathrm{H}$. An overview of infectious bursal disease. Archives Virology. 157:2047-2057. 2012.

MEEUSEN, E.N.T., WALKER, J., PETERS, A. ET AL. Current status of veterinary vaccines. Clinical Microbiology Reviews. 20: 489-510. 2007.

MICHELL B., GOMES A., BAIÃO N. et al. Effect of maternally-derived antibodies on the performance and immunity of broilers induced by in ovo or post-hatching immunizations with a live vaccine against infectious bursal disease. Revista Brasileira de Ciência Avicola. 11:5763. 2009.

MULLER, H., MUNDT, E., ETERRADOSSI, N. et al. Current status of vaccines against infectious bursal disease. Avian Pathology. 41:133-139. 2012.

NATIONAL RESEARCH CONCIL - NRC. Nutrient requirements of poultry. $9^{\text {th }}$ rev.ed. National Academy Press: Washington, D.C. 1994.

PEROZO, F., VILLEGAS, A.P., FERNANDEZ, R. et al. Efficacy of single dose recombinant herpesvirus of turkey infectious bursal disease virus (IBDV) vaccination against a variant IBDV strain.

Avian Disease. 53:624-628. 2009.

RAUTENSCHLEIN, S., VON SAMSONHIMMELSTJERNA, G., HAASE, C. A comparison of immune responses to infection with virulent infectious bursal disease virus (IBDV) between specifcpathogen-free chickens infected at 12 and 28 days of age. Veterinary Immunology Immunopatholy. 115: 251-260. 2007.

RODENBERG, J., SHARMA, J.M., BELZER, S.W. et al. Flow cytometric analysis of $B$ cell and $T$ cell subpopulations in specific-pathogen-free chickens infected with infectious bursal disease virus. Avian Disease. 38:16-21. 1994.
SAHAR, M. O., MAHASIN, A. S. A. A., RAHMAN, E. A. Residual pathogenic effects of Infectious Bursal Disease vaccines containing intermediate and hot strains of the Virus in broiler chickens. International Journal of Poultry Science. 3(6):415-418. 2004.

SCANAVINI NETO, H., ITO, N., MIYAJI, C., LIMA, E.D.A. et al. Infectious bursal disease virus: case report and experimental studies in vaccinated and unvaccinated SPF chickens and commercial broiler chicks. Revista Brasileira de Ciência Avicola. 6:41-54. 2004.

SCHAT K.A., SKINNER, M.A. Avian immunosuppressive diseases and imune evasion. in: DAVIDSON, N.F., KASPERS, B., SCHAT, K.A. Avian Immunology, 1st ed. Academic Press, Elsevier Ltd., 2008, pp. 299-322.

SHARMA, J.M; KIM, J; RAUTENSCHLEIN, S. et al. Infectious bursal disease virus of chickens: pathogenesis and immunosuppresion. Developmental and Comparitive Immunology. 24:223-235. 2000

WILLIAMS, A.E.; DAVISON, T.F. Enhanced immunopathology induced by very virulent infectious bursal disease virus. Avian Pathology. 34:4-14. 2005

ZHOU, X., WANG, D., XIONG, J. et al. Protection of chickens, with or without maternal antibodies, against IBDV infection by a recombinant IBDV-VP2 protein. Vaccine. 28:3990-3996. 2010. 